\title{
O ATLETA OLÍMPICO BRASILEIRO WILLY SEEWALD: MEMÓRIAS DO PRIMEIRO RECORDISTA NACIONAL DO LANÇAMENTO DE DARDO
}

\author{
DRA. JANICE ZARPELLON MAZO \\ Doutora em Ciências do Desporto pela Universidade do Porto (Portugal) \\ Professora do Programa de Pós Graduação Em Ciências do Movimento Humano da Escola de \\ Educação Física da UFRGS (Porto Alegre - Rio Grande do Sul - Brasil) \\ E-mail: janmazo@terra.com.br
}

\section{GRAD. TIAGO OVIEDO FROSI}

Bacharel em Educação Física pela Escola de Educação Física da Universidade Federal do Rio Grande do Sul (ESEF/UFRGS), Estudante de Mestrado Acadêmico do Programa de Pós-Graduação em

Ciências do Movimento Humano da Escola de Educação Física da UFRGS

(Porto Alegre - Rio Grande do Sul - Brasil)

E-mail: tiago.frosi@yahoo.com.br

\section{MS. PAULA ANDREATTA MADURO}

Mestre em Ciências do Movimento Humano pela Universidade Federal do Rio Grande do Sul (UFRGS), Professora da Faculdade de Educação Física da Universidade Luterana do Brasil (ULBRA) e Faculdade Integrada São Judas Tadeu

(Porto Alegre - Rio Grande do Sul - Brasil)

E-mail:pmadurol@gmail.com

\section{RESUMO}

O presente estudo registra a trajetória do atleta Willy Seewald, que se destacou no cenário esportivo sul-rio-grandense, nacional, e ainda teve uma participação nos Jogos Olímpicos de 1924, em Paris, na prova de lançamento de dardo. Para este estudo histórico foram consultados jornais, revistas, e documentos de acervo pessoal, além da produção de fontes orais por meio da gravação de entrevistas com familiares do atleta. A trajetória de Willy nos mostra que, para ser considerado um cavalheiro praticante do "bom esporte", no Brasil, os requisitos diferiam dos exigidos na Europa.

PALAVRAS-CHAVES: História; Esporte; Atletismo; Jogos Olímpicos. 
As referências sobre a participação brasileira nos Jogos Olímpicos de 1924 realizados em Paris, na França, são escassas. Talvez porque não há registro de medalhistas olímpicos brasileiros nestes jogos, como ocorreu na edição de 1920 na Antuérpia. No quadro de medalhas dos Jogos de Paris, os Estados Unidos ficaram em vantajoso primeiro lugar em relação aos outros países.

Todavia, este estudo não trata nem de atletas norte-americanos que lideraram o quadro de medalhas em Paris, como também não se detém na figura do herói olímpico daqueles Jogos, o inglês Harold Abrahams, que conquistou medalha de ouro na popular prova dos 100 metros, tradicionalmente vencida pelos norteamericanos. Ainda que a disputa entre o atleta norte-americano e o inglês tenha sido divulgada no Brasil por meio do filme Chariots of Fire, de 1981,' o foco desta pesquisa histórica nem mesmo se refere a um corredor, mas sim a um atleta que competiu em um esporte que até os dias atuais não possui muitos praticantes no país: o lançamento de dardo.

A presente pesquisa trata de registrar a trajetória do atleta brasileiro Willy Richard Franz Seewald, que se destacou não apenas no cenário esportivo sul-riograndense e nacional, mas, para além disso, se projetou enquanto atleta olímpico brasileiro, conquistando índice para participar dos Jogos Olímpicos de 1924 em Paris. O "admirável lançador" (IUGUENFRITZ, 1929, p. I), como era chamado pela imprensa escrita brasileira, foi o único atleta do estado do Rio Grande do Sul a integrar a delegação brasileira nos Jogos Olímpicos de Paris, em 1924. Assim foi chamado porque, além de obter os melhores índices nas provas de lançamento de dardo na época, era ele próprio quem fabricava os dardos. Foi, inclusive, a venda de seus dardos para alguns atletas, que permitiu a Willy Seewald custear sua participação em competições esportivas. Tratava-se, portanto, de um marceneiro, filho de imigrantes alemães, que alcançou o status de atleta olímpico e é reconhecido como o primeiro recordista nacional de sua prova (CONFEDERAÇÃO BRASILEIRA DE ATLETISMO, 20 I0).

Para este estudo² histórico foram consultadas fontes impressas como jornais, revistas, almanaques, e produzidas fontes orais por meio da gravação de depoimentos

I. Este filme foi divulgado no Brasil com o nome de "Carruagens de Fogo". A trilha sonora deste filme transformou a canção do músico grego Vangelis no hino de todos os corredores do mundo. Sobre a análise do filme, consultar Goellner (2007).

2. O presente trabalho não contou com apoio financeiro de nenhuma natureza para sua realização. 
com familiares do atleta. ${ }^{3}$ As fontes imagéticas foram obtidas do acervo particular da professora Simone Seewald. ${ }^{4}$ As fontes históricas selecionadas foram submetidas à análise documental. ${ }^{5}$

Os caminhos percorridos por Willy Seewald se confundem com a própria história do atletismo no Rio Grande do Sul, tendo em vista que os primeiros passos desta prática esportiva no Estado foram tardios se comparada a de outros esportes. Apesar de clubes promoverem a prática de algumas modalidades do atletismo, como por exemplo, a corrida e saltos, já no início do século XX (MAZO, 2003), essa prática esportiva se consolidou no cenário esportivo sul-rio-grandense somente no final dos anos de 1920. Assim, para entender o contexto esportivo do início do século $X X$, do qual emerge o atleta Willy Seewald, é preciso retomar, de forma breve, como se constituiu a prática do atletismo no Rio Grande do Sul.

\section{O ATLETISMO NOS CLUBES}

A prática do atletismo foi incorporada pelos clubes de Porto Alegre, a capital do estado do Rio Grande do Sul, na segunda década do século XX. Segundo o jornalista Tulio De Rose (apud AMARO JUNIOR, 1949, p. 137): "o atletismo nasceu no nosso Estado lá pelos anos de 1912 ou 1913". Clubes como a Turnerbund (atual Sociedade Ginástica Porto Alegre, fundada em 1867 - conhecida como SOGIPA), a Associação Cristã de Moços (ACM) e o Grêmio Foot-Ball Porto Alegrense foram os pioneiros (SILVA, 1997), seguidos pelos clubes náuticos, como foi o caso do Clube de Regatas Almirante Barroso (TEIXEIRA; MANARIN, 2003).

A primeira competição oficial de atletismo em Porto Alegre ocorreu em dois de abril de 1916 e contou com a participação de atletas uruguaios. Na época,

3. Todos os entrevistados concordaram em dar o depoimento e assinaram o termo de consentimento.

4. A professora Simone guardou alguns objetos da família após o falecimento dos pais, dentre os quais se destaca a medalha e o diploma de participação de Willy Seewald nos Jogos de Paris em 1924, fotografias, recortes de jornais e medalhas conquistadas em campeonatos nacionais. Além disso, Simone preservou lembranças do tio "herói olímpico", contadas pelo seu pai e sua mãe. A colaboração da Prof. ${ }^{a}$ Simone foi fundamental para recuperar fragmentos da vida esportiva de Willy Seewald. Sabe-se que no Brasil não é uma prática comum a preservação de documentos; em geral são veiculadas notícias de destruiçãa de documentação de pessoas, famílias, grupos e instituições. Os casos de iniciativas pessoais de preservação de acervos e a disposição de franqueá-los à consulta são poucos, mas não inexistentes. Um exemplo raro é o da professora Simone, que assim como seus pais, preocupou-se em guardar, cuidadosamente, o precioso acervo de Willy Seewald. Desta forma permitiu que, transcorridos 80 anos da sua morte, fosse recuperada as memórias da sua curta carreira esportiva e lançado um olhar sobre os horizontes do associativismo esportivo no Rio Grande do Sul.

5. Segundo Bardin (2000), a Análise Documental consiste em realizar operações de desmembramento do texto em unidades de significado, buscando desvendar seus diferentes sentidos e, posteriormente, a partir da análise dos dados, reagrupá-los e construir os eixos norteadores da pesquisa. 
o atletismo era pouco reconhecido por este nome e as pessoas associavam esta prática esportiva a ginástica, e em razão disso a competição acabou sendo chamada de "Festival de Ginástica". Neste evento, além do atletismo, houve competição de futebol, tênis e voleibol.

O crescimento da prática do atletismo em clubes resultou na realização do "I Campeonato Interclubes de Atletismo" na Turnerbund, em 24 de fevereiro de 1919 (SILVA, 1997). Os professores Georg Black e Ernest Graeff estruturaram o Departamento de Atletismo da Turnerbund e começaram a oferecer treinamentos para os atletas. A pista para prática do atletismo na Turnerbund foi construída em 1920. Atualmente, o local é conhecido como Estádio José Carlos Daudt e possui uma das quatro pistas homologadas pela Federação Internacional de Atletismo (CONFEDERAÇÃO BRASILEIRA DE ATLETISMO, 20I0).

Embora a Turnerbund tenha um papel destacado na entrada e difusão do atletismo no Rio Grande do Sul, as sociedades de ginástica das cidades de Novo Hamburgo e São Leopoldo, onde Willy Seewald começou a praticar esportes, contribuíram para impulsionar esta prática esportiva no Estado. Os esportes eram incentivados nas comunidades com forte presença de imigrantes alemães e descendentes.

Conforme Ramos (2000), as sociedades de ginástica, além de valorizar as raízes da cultura alemã e a educação moral da juventude, também promoviam o culto da saúde corporal. Dentre as práticas voltadas à saúde e educação moral dos imigrantes alemães e seus descendentes estava o atletismo. Foi na Leopoldenser Turnverein (Sociedade Ginástica de São Leopoldo) que Willy Seewald começou a prática da ginástica alemã e de esportes.

\section{O SPORTMAN WILLY SEEWALD}

Willy Richard Franz Seewald, apelidado de Didi pela família, nasceu em cinco de outubro de 1900, na localidade de Fazenda Fialho, município de Taquara, no Rio Grande do Sul. Era filho de Karl Robert Seewald - imigrante alemão que chegou ao Brasil em 1896 - e de Augusta Feisthauer Seewald - descendente de imigrantes alemães nascida no município de Montenegro (MÜLLER, 1986). Willy tinha uma irmã e dois irmãos, sendo que a irmã Marta faleceu ainda jovem. Edgar, seu irmão mais velho, dedicou-se por muitos anos à prática do remo e à natação. Erich, o irmão mais novo, desde os 16 anos de idade praticava a chamada, na época, ginástica de aparelhos (argola, barra, cavalo com alças, paralela e solo), a qual atualmente é denominada de ginástica artística, na Sociedade de Ginástica de São Leopoldo, além de jogar futebol no 
Clube Esportivo Nacional de São Leopoldo. Este clube, fundado em 1915, por um grupo de associados da Sociedade Orpheu (atual Sociedade de Canto de São Leopoldo), encerrou suas atividades e, no lugar do seu campo de futebol, foi construída uma zona residencial.

Willy seguiu os passos dos irmãos e, quando completou 18 anos de idade, também começou a jogar futebol no Clube Esportivo Nacional, onde permaneceu até o ano de 1922, mas também se dedicava às atividades da Sociedade de Ginástica. Como a maioria dos imigrantes alemães e seus descendentes que residiam na cidade, a família Seewald frequentava a Sociedade de Ginástica participando das atividades sociais e esportivas. As práticas corporais e esportivas oferecidas pela sociedade eram ministradas pelos instrutores Nestor Bir, Ervino Felipe Mohr e Raul Scherer em língua alemã (dialeto), conforme depoimento oral de Erich Seewald (SEEWALD, 200 I, p. 2).

Os irmãos Seewald faziam as sessões de ginástica alemã à noite, após o trabalho diário na fábrica de móveis da família, contou Erich em sua entrevista (SEEWALD, 200I, p. 2). Todos trabalharam quando jovens na fábrica de móveis dirigida pelo pai, cuja especialidade era a produção de esculturas em madeira para igrejas, casas e outros estabelecimentos. ${ }^{6}$

Willy aprendeu com seu pai o ofício da marcenaria e, quando começou a se dedicar exclusivamente ao atletismo, passou a fabricar seus próprios dardos. A aquisição de um dardo, naquela época, era dificultada não somente pelo custo do equipamento, mas também porque não era encontrado para a venda no Brasil. Para produzir os dardos, Willy utilizava uma madeira especial dividida em três partes, as quais eram coladas para diminuir a vibração, e "tinha outros segredos para fazer os dardos que ele não contava", relatou seu irmão (SEEWALD, 200 I, p. 5). Os dardos confeccionados artesanalmente por Willy eram testados no campo de futebol do Clube Esportivo Nacional, em São Leopoldo, como está registrado na Figura da página seguinte.

6. Faz-se a ressalva que algumas destas obras estão expostas no Museu Visconde de São Leopoldo, na cidade de São Leopoldo, Rio Grande do Sul. 


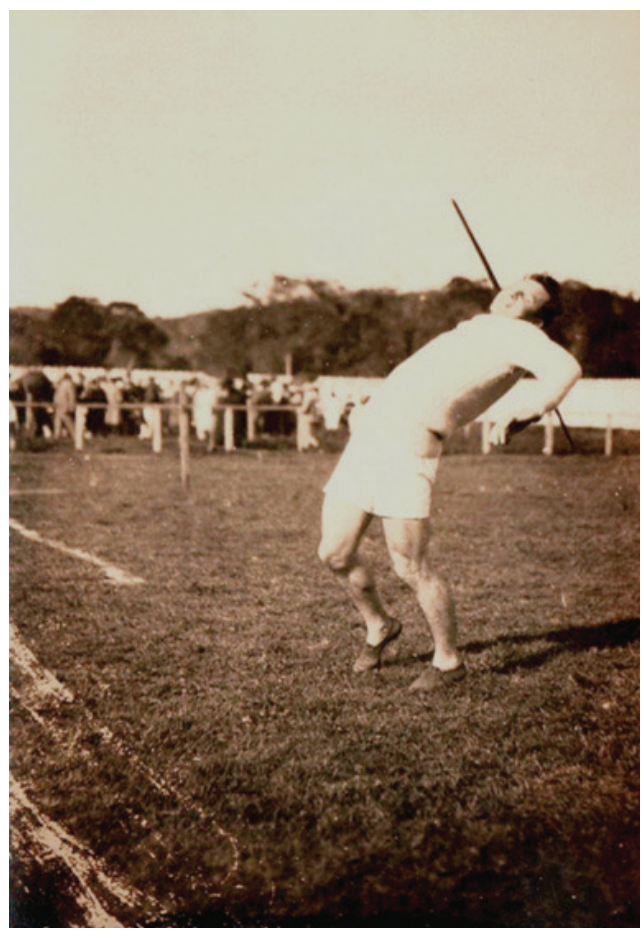

Figura I. Willy Seewald pratica o arremesso de dardo no campo do Clube Esportivo Nacional de São Leopoldo, em 1921.

Fonte: Acervo pessoal de Simone Seewald Albrecht.

Nos primeiros anos em que começou a praticar o lançamento de dardos, Willy já se destacou. No campeonato brasileiro de atletismo de 1921, "superou o recorde nacional por mais de três metros, quando alcançou 44,5m" (CONTRA RELÓGIO, 1997, p. 27). No ano seguinte, Willy integrou a delegação gaúcha, composta por oito atletas, que foi disputar os "Jogos Atléticos", comemorativos ao centenário da Independência do Brasil, na capital do país, na época a cidade do Rio de Janeiro. Devido aos resultados positivos obtidos nesses jogos, os atletas do Rio Grande do Sul garantiram sua participação na equipe brasileira que disputou o I Campeonato Latino-Americano de Atletismo, no Rio de Janeiro. Na disputa da prova de lançamento de dardo deste campeonato, "Willy Seewald obteve a marca de $54.515 \mathrm{~m}$ superando o chileno Arturo Medina, que até então era recordista sul-americano com a marca de 50,3m" (CONTRA RELÓGIO, 1997, p. 27). 
Até chegar aos Jogos Olímpicos de 1924, Willy realizou muitos treinos, geralmente à noite, pois durante o dia trabalhava na fábrica do pai. Quando viajava para as competições, era abrigado em casas de família ou em outros locais, conforme lembrou seu irmão: "não existia alojamento esse tipo de coisa, às vezes, nós ficávamos acampados em um salão de clube e todos dormiram no chão" (SEEWALD, 2000, p. 3). Os atletas não recebiam qualquer ajuda de custo para participar das competições, de acordo com o depoimento enfático de Erich Seewald: "Não, não, de dinheiro, nunca envolveu dinheiro, de maneira nenhuma" (SEEWALD, 200 I , p. 5). Os atletas daquela época, especialmente os oriundos das sociedades de ginástica, não concebiam qualquer apoio financeiro para a prática de esportes. Isso de certa forma explica a reação exaltada de Erich Seewald na entrevista, quando questionado sobre patrocínio recebido pelo irmão. As sociedades de ginástica daquele período primavam pelo esporte amador, e esta representação de um "bom esporte", que não deveria trazer retorno financeiro, transpareceu no depoimento do entrevistado.

É importante refletirmos, ainda, que Willy Seewald ultrapassou as fronteiras simbólicas que separavam o "homem simples" do gentleman. Ao mesmo tempo em que percebemos que este atleta suplantou as conhecidas barreiras do amadorismo, onde só eram aceitos na Europa como aficionados ou sportmen os homens membros de classes que detinham o poder econômico e político (GUTTMAN, 1978), vemos que possivelmente essas distinções não eram tão rigorosas no Brasil. Mesmo assim, pensar que, naquele período, um esportista, para ser reconhecido como tal, precisava estar vinculado a um determinado ethos, nos mostra mais uma das qualidades de Willy Seewald.

Willy era apontado como "o gigante físico, pelos seus músculos de aço, o gigante moral, pela sua educação de adversário correto e leal” (IUGUENFRITZ, 1929, p. I). Isto deve-se ao desempenho esportivo, mas também porque tinha atitudes esperadas de um atleta olímpico: no Brasil ele era considerado um sportman (IUGUENFRITZ, 1929). Sobre este aspecto, Guttman (1978), ao comentar as restrições elitistas do acesso ao esporte na Europa, nos lembra que nas regras da Regata de Henley de 1879, se lê: "ninguém pode ser considerado remador [...] caso seja ou tenha sido por negócio ou emprego por salário um mecânico, artesão ou operário". Entre aqueles excluídos da Henley estava o pai da princesa Grace de Mônaco (GUTTMAN, I 978, p. 3 I). Como um marceneiro, um artesão da madeira, Willy conquistou a vaga para os Jogos Olímpicos, indo disputar os mesmos Jogos que então eram terreno dos entusiastas europeus que se distinguiam de homens como ele, legitimando sua posição social através do discurso do puro esporte e do amadorismo. 
Provavelmente Willy enfrentou outros problemas, pois era filho de imigrante alemão, e sabe-se que estes imigrantes e seus descendentes foram hostilizados no Rio Grande do Sul em consequência dos acontecimentos da Primeira Guerra Mundial (GERTZ, 2005). Estudos dedicados à imigração alemã relatam diversas situações conflitantes enfrentadas por pessoas de ascendência alemã em associações esportivas, escolas, igrejas, entre outros locais. Neste período, muitos clubes esportivos cederam à pressão e desencadearam o processo de nacionalização, também chamado de "abrasileiramento", mudando o nome original e adotando a língua portuguesa como língua oficial no estatuto e atas (MAZO, 2003; 2007).

Willy Seewald conseguiu chegar longe, considerando as dificuldades financeiras, as precárias condições de treinamento e a incipiente organização das competições de atletismo no Brasil nos anos 1920. Com seus dardos Willy começou a transpor índices regionais, nacionais e sul-americanos, mas a grande surpresa foi sua convocação para, junto com atletas das grandes metrópoles brasileiras, Rio de Janeiro e São Paulo, fazer parte da delegação brasileira que disputaria a oitava edição dos Jogos Olímpicos da Era Moderna na cidade de Paris, na França, em 1924.

\section{A PARTICIPAÇÃO NOS JOGOS OLÍMPICOS DE PARIS}

Willy Seewald era o único atleta do Rio Grande do Sul que integrou a delegação brasileira, composta por 12 atletas homens, que representaram o país nos Jogos de Paris. Segundo depoimento de seu irmão, Willy recebeu ajuda de uma tradicional família de imigrantes alemães residente em Porto Alegre, para participar dos Jogos Olímpicos em Paris, pois não tinha recursos financeiros suficientes para fazer a viagem (SEEWALD, 2000, p. 8). Inicialmente, estava prevista uma ajuda "do governo brasileiro no valor de 350 contos de réis para a preparação e viagem da delegação aos Jogos de Paris" (RUBIO, 2006, p. 105). Entretanto, houve a cassação da verba e retirada oficial da inscrição da delegação brasileira devido aos problemas de organização da Confederação Brasileira de Desportos (CBD). Então, "a Federação Paulista de Atletismo realizou uma campanha de fundos, patrocinada pelo jornal O Estado de São Paulo, para conseguir a verba necessária para o pagamento das despesas de viagem e alojamento" (RUBIO, 2006, p. 105). Após o impasse, Willy Seewald, que nunca tinha viajado para o exterior, foi à França e posteriormente à Alemanha, visitar parentes.

A oitava edição dos Jogos Olímpicos da Era Moderna realizados em Paris iniciou no dia três de maio de 1924, contando com 3.089 atletas de 44 países. Houve a ausência de países considerados potência esportiva. No cenário internacional, os conflitos acirrados pela Primeira Guerra Mundial ainda não tinham cicatrizado, tanto que a Alemanha, a Áustria e Rússia não enviaram suas delegações para Paris. 
A expectativa de sucesso da delegação brasileira era grande, afinal, na edição anterior dos jogos, em 1920, na Antuérpia, os atletas do tiro tinham conquistado, inesperadamente, as três primeiras medalhas olímpicas brasileiras. Porém, em Paris, os atletas brasileiros não conquistaram medalhas. No lançamento de dardo, os medalhistas olímpicos foram respectivamente: Jonni Myyrä, da Finlândia, com a distância de 62,96 m; Gunnar Lindström, da Suécia, alcançando 60,92 m e Eugene Oberst, dos Estados Unidos, atingindo 58,35 m. Willy Seewald obteve o sexto lugar na prova de lançamento de dardo, com a distância de 49,39 m, recebendo uma medalha e diploma de participação, conforme figuras a seguir.

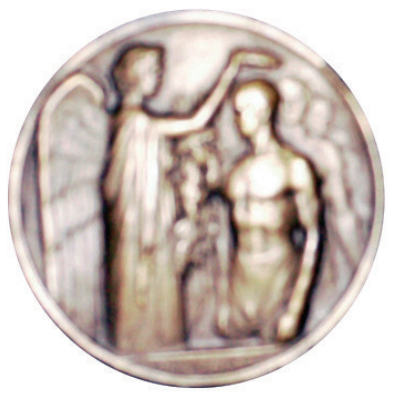

Figura 2. Medalha de participação concedida a Willy Seewald nos Jogos Olímpicos de 1924. A face representa a coroação do atleta pela deusa Nikea

Fonte: Acervo pessoal de Simone Seewald Albrecht.

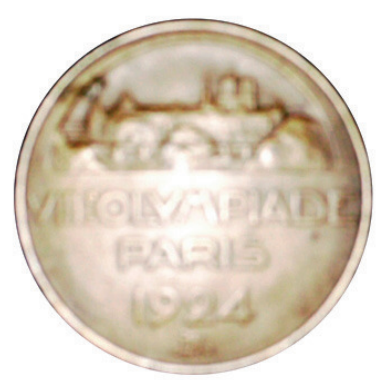

Figura 3. Medalha de participação concedida a Willy Seewald nos Jogos Olímpicos de 1924. Na face uma imagem de Paris seguida das inscrições VII Olympiade Paris 1924.

Fonte: Acervo pessoal de Simone Seewald Albrecht. 


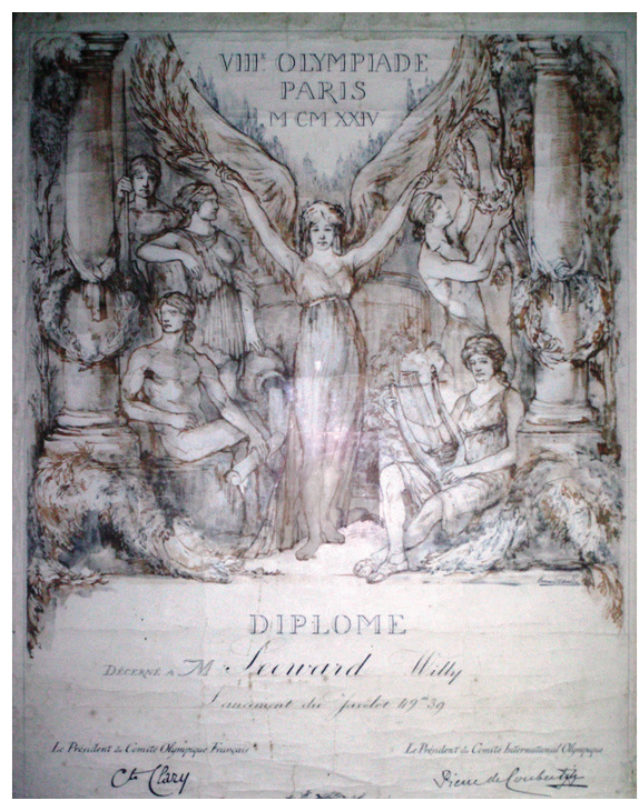

Figura 4. Diploma recebido por Willy Seewald pela participação nos Jogos Olímpicos de 1924. Na parte inferior constam os dados do atleta e sua marca na competição: $49 \mathrm{~m} 39 \mathrm{~cm}$.

Fonte: Acervo pessoal de Simone Seewald Albrecht.

O lançamento de dardo é uma das provas de campo do atletismo que faz parte do programa olímpico moderno desde 1908. O formato moderno do atletismo remonta a meados do século XIX e está dividido em provas de pista, de campo, marcha atlética e provas combinadas, que integram o programa dos campeonatos mundiais de atletismo. No lançamento de dardo, a primeira marca registrada pertence a Adolf Wigert, da Suécia, conquistando a distância de 35,8 I m em 1886, e o primeiro recorde da Federação Internacional de Atletismo (IAAF) foi obtido pelo seu compatriota Eric Lemming que, em 29 de setembro de 1912, na cidade de Estocolmo, atingiu a marca de 62,32m. Este recorde foi superado nos Jogos Olímpicos de Paris por Jonni Myyrä, da Finlândia.

Após o encerramento dos Jogos de Paris, Willy Seewald viajou para a cidade de Colônia, na Alemanha, a fim de visitar parentes. Durante sua estadia na cidade foi convidado para participar da inauguração de uma pista de atletismo. Tal fato encontra-se registrado em documento que pertence ao primo de Willy Seewald, 
residente na Alemanha, conforme depoimento de Erich Seewald (SEEWALD, 200 I , p. I I). Na Figura abaixo consta a carta recebida por Willy Seewald, com o convite para a visita aos parentes.

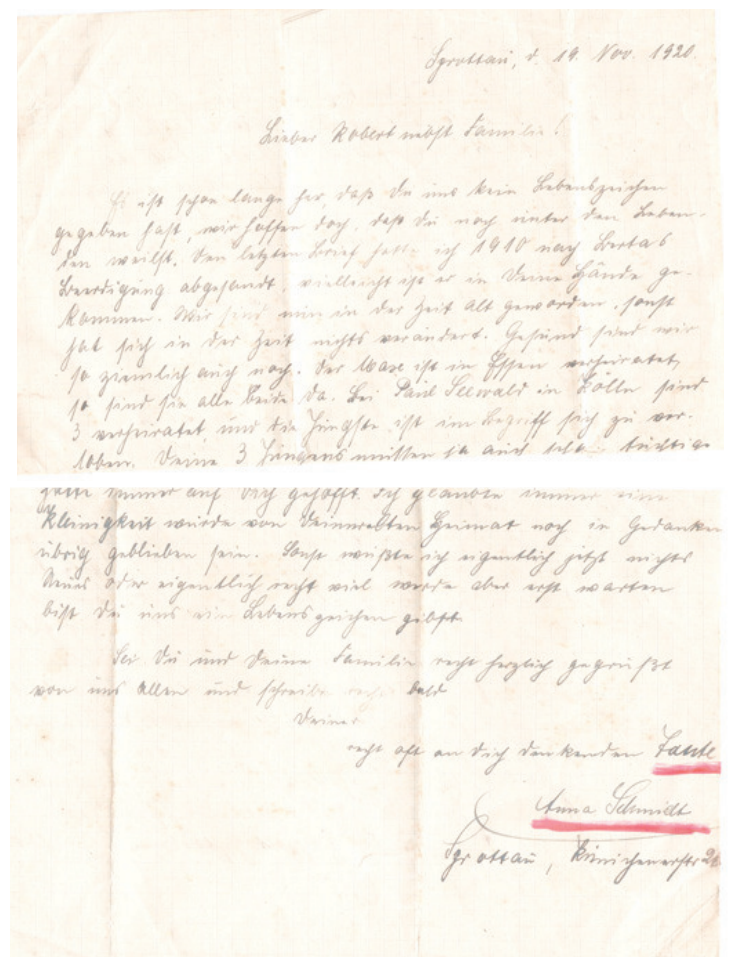

Figura 5. Carta redigida em idioma alemão por parente de Willy Seewald, residente na Alemanha, combinando a visita.

Fonte: Acervo pessoal de Simone Seewald Albrecht.

Quando Willy retornou ao Brasil, depois de passar um período na Alemanha conhecendo os parentes por parte da família de seu pai, retomou a participação em competições. Viajou para São Paulo a fim de disputar o I Campeonato Nacional de Atletismo em 1925, vencendo a prova com a marca de 54, I I m e obtendo o reconhecimento do primeiro recorde brasileiro no lançamento de dardo (CONFEDERAÇÃO BRASILEIRA DE ATLETISMO, 20 I0). Nos dois anos que se seguiram sagrou-se campeão brasileiro e sempre "mantendo o mesmo nível técnico" 
(DE ROSE, 1949, p. 138). No segundo ano do campeonato nacional, em 1926, alcançou 56, I7m e no III Campeonato Nacional de Atletismo, em 1927, atingiu a marca de 54,90m (CONTRA RELÓGIO, 1997, p. 27), conforme diploma abaixo.

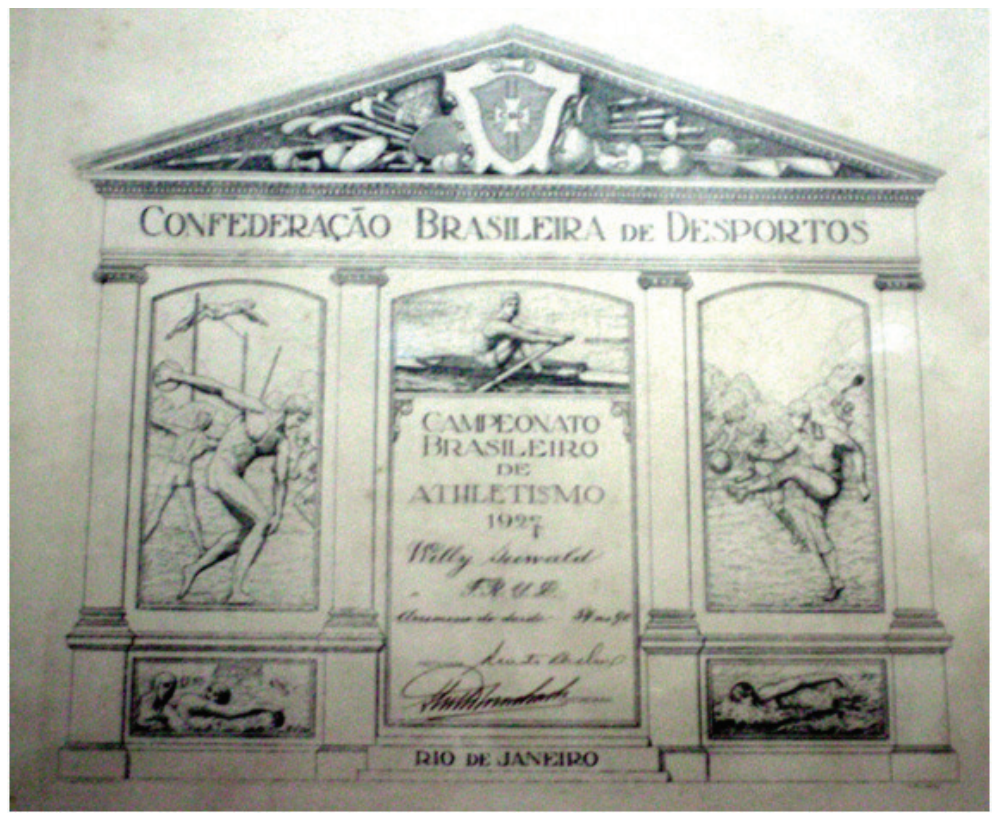

Figura 6. Diploma pela participação de Willy Seewald no "III Campeonato Brasileiro de Atletismo", no Rio de Janeiro em 1927. Na parte inferior do diploma consta sua marca na competição: $54 \mathrm{~m} 90 \mathrm{~cm}$.

Fonte: Acervo pessoal de Simone Seewald Albrecht.

Com a conquista do índice nacional e sul-americano, Willy Seewald provavelmente estaria entre os atletas convocados para participar dos Jogos Olímpicos de 1928, caso o Brasil tivesse enviado uma delegação para competir nesses jogos realizados em Amsterdã (Holanda). $\bigcirc$ Brasil não participou desta edição porque o país atravessava uma crise econômica, a qual impediu que houvesse recursos suficientes para enviar uma delegação. Ainda que possam ter outros motivos, importa que este fato foi lamentável, particularmente para Willy Seewald, que poderia ter conquistado sua última medalha neste evento. No final do ano de 1928 , o atleta adoeceu e, inesperadamente, faleceu no começo do mês de fevereiro de 


\title{
1929 (BRENDEMEIR, 2009; COMUNIDADE EVANGÉLICA DE CONFISSÃO LUTERANA EM SÃO LEOPOLDO, I5/05/2009).
}

\section{IN MEMORIAN: UM MINUTO DE SILÊNCIO PARA WILLY SEEWALD}

A morte de Willy surpreendeu a todos. Estava casado fazia dois anos, morando na cidade de Canoas, no Rio Grande do Sul, quando sentiu fortes dores no abdômen e foi levado com urgência para o Hospital da Beneficência Portuguesa, em Porto Alegre. O irmão dele, Erich, contou em depoimento emocionado que, no hospital, o médico americano Basílio Septor queria fazer a cirurgia: "ele queria abrir, pra ver. Papai disse não. O pai disse: não, agora é tarde" (SEEWALD, 200 I , p. 12). Logo em seguida, ainda no hospital, o atleta Willy Seewald faleceu em razão de apendicite, aos 28 anos de idade. A jovem esposa ${ }^{7}$ de Willy casou novamente anos depois de sua morte e teve um filho, Friedrich Willy Brendemeir, que foi localizado pelos pesquisadores em 2009, com 73 anos. ${ }^{8}$

A ausência do atleta brasileiro foi lembrada nos eventos esportivos realizados no ano de 1929:

\begin{abstract}
Hoje, em que os olhos de todo o Brasil esportivo estão voltados para a nossa cidade [Rio de Janeiro], porque ela vai ser teatro do maior acontecimento do ano, que é o Campeonato de Atletismo do Brasil, não podemos deixar esquecido o nome de Willy Seewald, o grande atleta gaúcho [nascido no Estado do Rio Grande do Sul] que a dois de fevereiro do corrente ano foi arrebatado pela morte. (IUGUENFRITZ, 1929, p. I).
\end{abstract}

No discurso de abertura do VII Torneio de Atletismo, promovido pela Liga das Sociedades de Ginástica do Rio Grande do Sul no estádio da Turnerbund, como também no $5^{\circ}$ Campeonato Estadual de Atletismo, sob o patrocínio da Liga Atlética Rio-Grandense (LARG), o falecimento de Willy foi referido com pesar. Em ambos os eventos a cerimônia de abertura estava sendo prestigiada pelo presidente (expressão da época) do Estado do Rio Grande do Sul, Getúlio Vargas e outras autoridades (REVISTA DO GLOBO, 1929, n. 17, p. 37 apud MAZO, 2004). No mesmo ano, no $5^{\circ}$ Campeonato Brasileiro de Atletismo, realizado no final de agosto e começo do mês de setembro, no estádio do Clube de Regatas Vasco da Gama, na cidade do Rio de Janeiro, o recordista sul-americano do lançamento de dardo não estava presente, mas foi lembrado tanto na abertura do evento

7. A esposa de Willy faleceu em 1996 aos 97 anos de idade.

8. O Sr. Friedrich levou os pesquisadores para visitar o túmulo de Willy Seewald no cemitério de São Leopoldo. 
quanto em crônica publicada num jornal carioca e, posteriormente, reproduzida no jornal de São Leopoldo (conforme FIGURA abaixo).

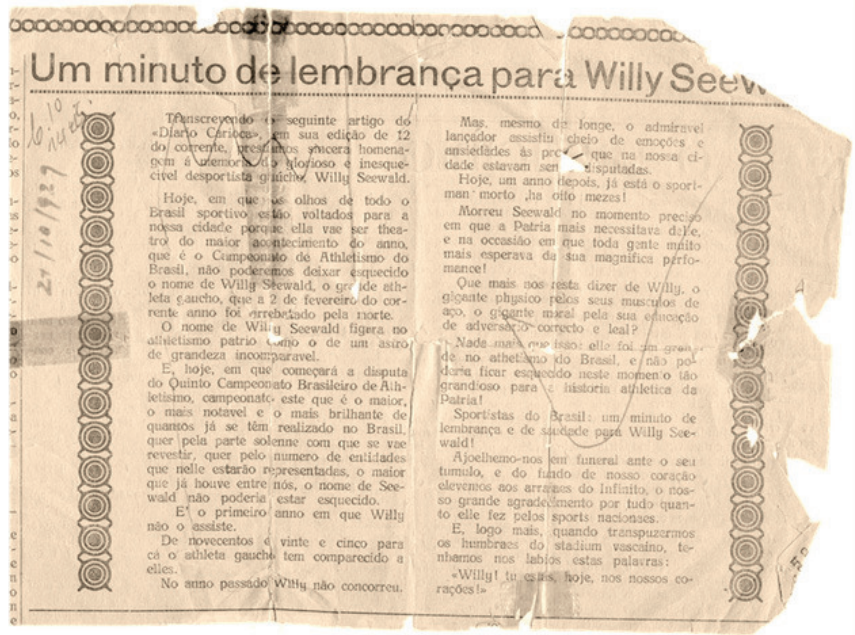

Figura 7. Reportagem de jornal do Rio de Janeiro publicada em homenagem ao atleta Willy Seewald, após seu falecimento no ano de 1929.

Fonte: Acervo do Museu Visconde de São Leopoldo, 2009.

Willy Seewald teve uma vida curta, mas seu recorde durou quase 30 anos. $\bigcirc$ recorde sul-rio-grandense conquistado pelo ateta foi superado, após 27 anos, por Nicanor Missaglia, do Grêmio Foot Ball Porto Alegrense, que obteve a marca de 58,2 metros no ano de 1949. Já o índice brasileiro no lançamento de dardo permaneceu até 1957, quando um atleta do Rio de Janeiro ${ }^{9}$ superou a marca de Willy Seewald.

9. O nome do atleta carioca não foi localizado nas fontes e nem mesmo no site da Confederação Brasileira de Atletismo. 


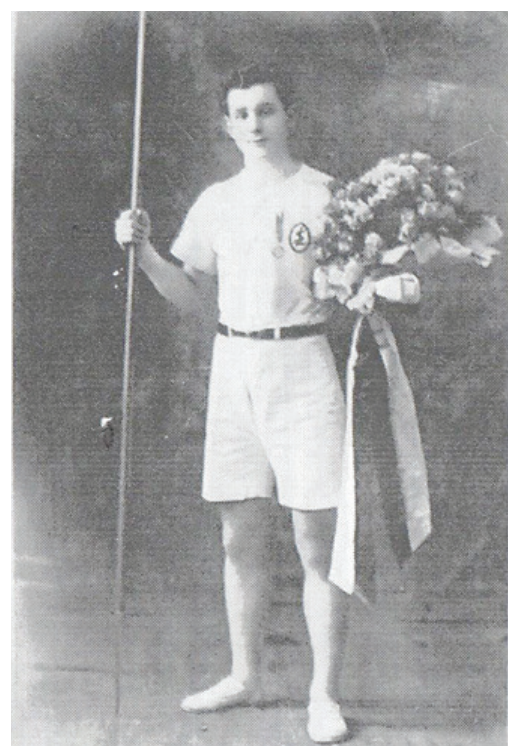

Figura 8. Foto de Willy Ricardo Seewald, o "admirável lançador".

Fonte: Acervo pessoal de Simone Seewald Albrecht.

\section{CONSIDERAÇÕES FINAIS}

O caminho percorrido do Rio Grande do Sul a Paris pelo atleta Willy Seewald é instigante, ainda mais que estamos tratando da história de um atleta brasileiro no início do século $X X$. Willy ascendeu rapidamente no atletismo e, em menos de 10 anos, conquistou recordes regionais, nacional e sul-americano, demonstrando um significativo desempenho esportivo, tendo em consideração as condições oferecidas aos atletas na época. Quem sabe até onde Willy chegaria, afinal de contas ele faleceu logo após conquistar mais um recorde no lançamento de dardo.

Dos Jogos Olímpicos de Paris,Willy Seewald não trouxe as cobiçadas medalhas de ouro, prata ou bronze, mas recebeu uma medalha olímpica de participação, o que foi mais do que suficiente para ser lembrado. Ele figura como o único atleta sul-rio-grandense convocado para integrar a delegação brasileira que foi aos Jogos Olímpicos de 1924, composta, exclusivamente, por atletas de São Paulo e Rio de Janeiro. Sem dúvida, Willy contribuiu para que o Rio Grande do Sul fosse reconhecido como um dos polos do atletismo nacional. Além do mais, ele foi um 
atleta que representou o Brasil em uma edição dos Jogos Olímpicos e isto, considerando a ausência de uma política esportiva brasileira (TUBINO, 1997) na época, já é muito significativo para o cenário esportivo do Brasil.

Ao percorrer a trajetória de Willy Seewald, chamamos a atenção para a contribuição das associações esportivas fundadas pelos imigrantes alemães e seus descendentes no Rio Grande do Sul. Em particular, as sociedades de ginástica atuaram de forma relevante na formação de atletas, mas também promovendo o esporte enquanto um dos pilares para a educação físico-esportiva e moral dos cidadãos. O caso de Willy Seewald revela a importância da Sociedade de Ginástica de São Leopoldo na formação de atletas amadores.

O registro dos voos dos dardos lançados por Willy Seewald, que direcionaram sua vida, possibilitou que reconstruíssemos suas memórias. A busca pelas fontes históricas que permitiram conhecer um pouco mais sobre Willy foi um desafio, pois são escassas, tanto as impressas quanto as orais. ${ }^{10}$ Poucas evidências restaram, pois muito se perdeu ao longo dos anos ou foi extraviado ou ainda destruído, " quando ocorreu o processo de nacionalização das sociedades de ginástica no período da Primeira Guerra Mundial (1914-1918), durante o Estado Novo (1937-1945) e na Segunda Guerra Mundial (1939-1945).

A trajetória deste atleta, cujas memórias procuramos preservar com este estudo, nos dá ainda a possibilidade de realizar uma breve reflexão acerca das questões do discurso que defendia a preservação de um amadorismo, de um ethos elitista que estava presente nas sociedades europeias da época. $\bigcirc$ caso de Willy sugere que essas construções culturais eram importadas ao Brasil, mas sofriam a influência das relações sociais locais e se modificavam, produzindo-se novas representações do que viria a ser um sportman. Como as fontes revelam, para ser considerado um cavalheiro praticante do "bom esporte", no Brasil, os requisitos diferiam dos exigidos em países da Europa.

10. No que diz respeito às fontes orais, gravamos uma entrevista com o Sr. Erich Seewald, único irmão vivo de Willy na época. Uma nova entrevista estava prevista quando iniciamos a construção do presente texto, mas fomos surpreendidos pela triste notícia que o Sr. Erich tinha falecido aos 88 anos de idade em 2005. Dona Ligia, esposa do Sr. Erich e cunhada de Willy, que acompanhou a primeira entrevista, também faleceu em 2008, com mais de 90 anos de idade. Lamentavelmente se extinguiu a possibilidade de uma segunda entrevista com os familiares próximos.

I I. Felizmente, no Museu Visconde de São Leopoldo, localizado na cidade de São Leopoldo/Rio Grande do Sul restaram alguns recortes de jornais guardados em uma pequena caixa de papel doada por parentes de Willy Seewald. 
The Brazilian Olympic Athlete Willy Seewald: memoirs of the first national throwing javelin's record-breaker

ABSTRACT: This study records Willy Seewald's athletic trajectory, which was an eminent athlete on regional and national sports scenery and also participated of the 1924 Olympic Games in Paris, on throwing javelin event. The study was made by consulting printed sources like journals, magazines and personal documents, and oral sources recorded through interviews with the athlete's family. Willy's trajectory shows us that to be considered a gentleman, a good sport practitioner, in Brazil the requirement differs from Europe's. KEYWORDS: History; Sport; Athletics; Olympic Games.

\section{El deportista olímpico brasileño Willy Seewald: memorias del primero plusmarquista nacional de lanzamiento de jabalina}

RESUMÉN: El presente estudio representa la trayectoria del atleta Willy Seewald, quien se destacó en el escenario deportivo sur rio-grandense, nacional, y además con una participación en los Juegos Olímpicos de 1924 (París). Además de esta importante contribución. Willy Seewald fue plusmarquista brasileño y sudamericano de lanzamiento de jabalina. Para esto estudio histórico fueran consultados fuentes impresas, como periódicos, revistas, documentación privado, e producidas fuentes orales a través del registro de declaraciones de familiares del atleta. La trayectoria de Willy nos muestra que para ser considerado un caballero profesional del "bueno deporte" en Brasil, los requisitos difieren de los exigidos en Europa.

PALABRAS-CLAVE: Historia; Deporte; Atletismo; Juegos Olímpicos

\section{REFERÊNCIAS}

ALBRECHT, S. Simone Seewald Albrecht: depoimento, I 5 maio 2009. São Leopoldo, 2009. BARDIN, L. Análise de conteúdo. Lisboa: Edições 70, 2000.

BRENDEMEIR, F. Friedrich Willy Brendemeir: depoimento, 18 jun. 2009. São Leopoldo, 2009. COMUNIDADE EVANGÉLICA DE CONFISSÃO LUTERANA EM SÃO LEOPOLDO (São Leopoldo). Livro de Registro de Óbitos: declaração de falecimento de Willy Richard Franz Seewald, São Leopoldo, v.3, n. 5, I863-194I .Consulta realizada em: I 5 maio 2009.

CONFEDERAÇÃO BRASILEIRA DE ATLETISMO (Brasil). Histórico das Provas - Masculino. Portal da Confederação Brasileira de Atletismo. Disponível em: <http://www.cbat.org.br/ provas/historico_masculino.asp>. Acesso em: 20 jan. 2010.

DE ROSE, T. Campeonato de atletismo. In: AMARO Jr., J. Almanaque esportivo do Rio Grande do Sul. Porto Alegre: Tipografia Esperança, 1949. 
GERTZ, R. E. O Estado Novo no Rio Grande do Sul. Passo Fundo: EdUPF, 2005.

GOELLNER, S. V. História e cultura do movimento olímpico: a reconstrução cinematográfica dos Jogos Olímpicos de Paris - 1924. In: RUBIO, K. et al. (Org.). Ética e compromisso social nos estudos olímpicos. Porto Alegre: EDIPUCRS, 2007. p.203-2I 6.

GUTTMAN, A. From ritual to record: the nature of modern sports. New York: Columbia University, 1978.

IUGUENFRITZ, A. Um minuto de lembrança para Willy Sewald. Jornal de São Leopoldo, São Leopoldo, n. 279, 21 out. 1929.

JORNAL O IMPARCIAL, Rio de Janeiro. Suplemento esportivo, 16 set. 1922.

JORNAL UNIÃO ORGAM REPUBLICANO, São Leopoldo, I I fev. 1929.

JORNAL DIÁRIO CARIOCA, Rio de Janeiro. Um minuto de lembrança para Willy Seewald, 12 set. 1929.

MAZO, J. Z. A emergência e a expansão do associativismo desportivo em Porto Alegre ( 1867 1945): espaço de representação de identidades teuto-brasileira. 2003. 366 f. Tese (Doutorado em Ciências do Desporto) - Universidade do Porto, Porto, 2003.

MAZO, J. Z. O Esporte e a Educação Física na Revista do Globo: catálogo (I 929- 1967). Porto Alegre: FEFID/PUCRS; ESEF/UFRGS, 2004 (I 3 CD-ROM).

MAZO, J. Z. A nacionalização das associações esportivas em Porto Alegre (1937-1945). Movimento, Porto Alegre, v. 13, p. 43-63, 2007. http://seer.ufrgs.br/Movimento/article/ view/3563. Acesso em: 15 jan. 2009.

MAZO, J. Z.; MADURO, P. A trajetória de um atleta olímpico gaúcho: Willy Seewald, o admirável lançador. In: REPPOLD FILHO, A. et al. (Org.). Olimpismo e educação olímpica no Brasil. Porto Alegre: Ed. da UFRGS, 2009. p. 23 I-240

MÜLLER, T. Sociedade ginástica cem anos de história. São Leopoldo: Rotermund, 1986.

RAMOS, E. O teatro da sociabilidade: os clubes sociais como espaço de representação das elites urbanas alemãs e teuto-brasileiras - São Leopoldo 1858-1930. Tese (Doutorado em História) - Universidade Federal do Rio Grande do Sul, Porto Alegre, 2000.

REVISTA CONTRA RELÓGIO, São Paulo, n. 47, p. 26-27, ago. 1997,.

REVISTA DO GLOBO. Porto Alegre: Globo, n. 17, 1929, p. 37 apud MAZO, J. (Org.). Catálogo do Esporte e da Educação Física na Revista do Globo. Porto Alegre: Edipucrs, 2004.

RUBIO, K. Medalhistas olímpicos brasileiros: memórias, histórias e imaginário. São Paulo: Caso do psicólogo: FAPESP, 2006.

SEEWALD, E. Erich Seewald: depoimento. Porto Alegre: 2000. 
SEEWALD, E. Erich Luis Seewald: depoimento. São Leopoldo, 2001.

SILVA, H. SOGIPA: uma trajetória de 130 anos. Porto Alegre: Palloti, 1997.

TEIXEIRA, M; MANARIN, R. História do atletismo gaúcho. Portal Atletismo RS. Disponível em: <http://www.atletismors.hpg.com.br>. Acesso em: I 5 jan. 2009.

TUBINO, J. M. G. Esporte, política e jogos olímpicos. In: TAMBUCCI, P. L.; MARIZ DE OLIVEIRA, J. G.; COELHO SOBRINHO, J. Esporte e jornalismo. São Paulo: CEPEUSP, 1997. p.19-23.

Recebido: 16 set. 2010

Aprovado: 29 jun. 201 I

Endereço para correspondência:

Janice Zarpellon Mazo

Rua Lucas de Oliveira, n² 2507/402

Bairro Petrópolis

Porto Alegre-RS

CEP: 90460-00 I 